\title{
TEACHING ARABIC ORAL AND WRITTEN COMMUNICATION AMONG THE YORUBA SPEAKERS IN NIGERIA: A CONTRASTIVE ANALYSIS
}

\author{
Muhammad Olatunde Yaqub ${ }^{1}$ \\ Tijani Akinola Mogaji ${ }^{2}$ \\ Abdurauf Kehinde Abioye ${ }^{3}$ \\ Lagos State University, Lagos State Nigeria \\ 1tyaqub2003@yahoo.com \\ 2tijanimogaji@yahoo.com \\ 3rabioye@yahoo.com
}

\begin{abstract}
The teaching and learning of Arabic language especially in the non-native environment require a simplified method to make the job a more fruitful enterprise. This paper explores the application of a contrastive analysis of both the target language and the native language in encouraging, motivating and simplifying the teaching and learning of oral Arabic communication skill among the native Yoruba speakers. The work identifies the major areas of difficulties facing the students from this region. This includes phonetics, phonology and agreement relation (otherwise known as concord in grammar). The agreement consists of gender, person, terms and numbers which form a major component of grammatical Arabic sentence. It is observed that understanding these major areas will enhance the performance of the students in achieving the required standard in Arabic oral communication. The paper concludes that Arabic phonetics, phonology and grammar are more elaborate than those of Yoruba. Hence, the instructors need to focus more attention on these difficult areas; especially those areas that do not exist in the native language (Yoruba).
\end{abstract}

Keywords: Arabic, Yoruba, contrastive, phonology, grammar.

\section{Introduction}

Africa had contact with Arabic language prior to the advent of Islam in the continent in the early part of the 7th century. As a consequence, the language had wider circulation among the people of Africa and later became the official language in parts of the Africa such as Egypt, Algeria, Morocco, Libya, and Tunisia. As early as the 9th century, Northern Nigeria for instance, has attracted the attention of the Arab geographers, travelers, and traders. In their curiosity for intellectualism and 
particularly for economic purposes, Arab travelers found themselves in these regions writing reports of their experiences. These Arab geographers, travelers and traders in their desire to tap the economic resources of the flourishing TransSaharan trade for their countries produced a corpus of literary works in Arabic. These Arabic writings offered information concerning nations, economic data, social life, international trade as well as merchant routes, religious beliefs and customs, and cosmographies. The Arabic sources are of tremendous significance to the early history of Africa particularly as it covered a period roughly between the 8th and 15th century. The Arabic literary heritage on Kanem-Borno travelogues of the itinerant Arab Geographers was later regarded as first hand materials for African historical reconstruction.

The level of Arabic usage reached its apogee in Hausa land in the $19^{\text {th }}$ century during the celebrated Islamic reform of Shaykh Uthman b. Fodio. During the period, the language was widely used and its standard was very high. Consequently, it was adopted by the Sokoto caliphate as its official language and served several purposes in the society before the colonialists gained control of the North in 1903. Among other things, it was the medium of official communication and administration, a tool of dissemination of Islamic belief, a means of historical documentation and articulation of legal rules. Over the ages, Arabic words made systematic inroad into the Hausa language, therefore, many commercial, sociocultural and religious vocabularies became part and parcel of the Hausa language and have remained so till today.

Similarly, the Arabic language has a relatively long history in Yoruba land, though its history in the area may not be as long as in Kanem-Bornu and Hausa land. It began not only with the history of Islam but also with the trade between the Arabs from North Africa and the Yoruba land long before the arrival of the English colonialists. Needless to say, Islam served as an impetus to the study of Arabic language, not only in Yoruba land but also in the entire West Africa sub-region. It is also important to note that Arabic has witnessed tremendous development in Nigeria. The standard is not only high but Nigerian Arabic writers have also begun writing short stories, dramas and pithy sayings which were hitherto unexplored in their writings.

Yoruba language is one of the major languages in Nigeria which is widely spoken in Lagos, Ogun, Ondo, Oyo, Osun, Ekiti and Kwara states. It is also spoken in Delta, Edo and the western part of Kogi state, though the speakers of Yoruba in these three states are less in number than those in the seven states mentioned. According to the center for word languages/language materials project, University of California, Los Angeles (www.imp.ucla.edu) (accessed on December $6^{\text {th }}, 2011$ ), Yoruba is spoken by around 30 million people in Nigeria as a first language. The number rises to 32 million if second language speakers are included. Different researchers like Fafunwa (2008) have shown that Yoruba language is equally spoken in some west African countries like Benin Republic, Togo, Ghana, and Cote d'voire. Other places include Cuba, Brazil, Haiti, and Trinidad and Tobago in southern part of America. The widespread use of the Yoruba language has brought about variations in its spoken form in all these aforementioned areas and this has led to increment in the numbers of dialects of the Language. Despite its numerous dialects the Yoruba 
language has a dialect that is accorded more social status than the others. It is referred to as the standard Yoruba (SY). This standard form is the language of education, judiciary, administration and media, which also connects all other dialects of the language.

The Arabic and the Yoruba languages have interacted for centuries since the advent of the Arabic-Islamic civilisation in the south-western region of Nigeria during the $14^{\text {th }}$ century. The Arabic language is the lingua franca of Islam which serves the religious purposes of Muslims all over the world, since the bulk of the fundamental rituals or creed of worship of Islam is rooted in Arabic language. Therefore, many Arabic lexical items covering virtually all strata of life have found their way into the Yoruba language, to the extent that numerous Yoruba native speakers would believe that such linguistic usages are basically of Yoruba origin. Previous researchers in this area of study such as Gbadamosi (1978), Malik (1990, 1999), Abubakre (1983, pp. 13-14), Mogaji (2009a) and Onibon (2011) have discussed this issue extensively.

\section{The nature of Arabic oral communication as a second language}

In order to communicate effectively in Arabic, an aspiring learner needs to be wellgrounded in the articulation of the Arabic sounds/phonemes and also possess an adequate Arabic vocabulary bank. Importantly, the learner must have a mastery of Arabic syntax. All these are referred to as linguistic competence. However, while this is necessary, it is not sufficient for someone who wants to communicate competently in another language. Communicative competence includes linguistic competency and also a range of other socio-linguistic and communication skills that enable the speaker to know how to say what, to whom and when (Hymes, 1974). Communicative competence is not restricted to the spoken language alone, but involves the writing as well. It is also context specific, which means that a competent communicator in Arabic language knows how to make choices specific to the situation. This is different from performance, which is what an individual does. It is also worthy of note that the nature of Arabic selected to be taught is a written kind of Arabic and not the spoken type. Thus, students of Arabic are often taught the grammatical rules and vocabulary that are more characteristic of written Arabic and are given very little or no training in the spoken form. The contextual forms which feature the characteristics of the written Arabic are emphasised in teaching while the oral form are being neglected as shown in the examples below:

$$
\text { Arabic English }
$$

1. (a) A?taytukakita:bahu-------context (I gave you his books)

(b) A?taytukkita:bah--------oral ( " )

2. (a) Aynaanta----------context (where are you)

(b) Aynant-------------oral ( " )

It is quite clear, from the above illustrations that the contextual and the oral form of the language are very different entities. In essence, concentrating only on one aspect of the language, while neglecting the other, amounts to teaching a very artificially-stilled form of speech. To teach Arabic oral communication sufficiently 
well in order to enable the learners speak and read it effectively would require making a fully practical study of the oral communication skills involved in language speaking (Malik, 1980).

\section{The concept of contrastive analysis}

In multi-lingual societies such as Nigeria, there often exists a national language which every citizen aspires to master for effective social interaction. The situation produces various types of bilinguals and multi-linguals with varied levels of competence. One major linguistic instrument that language researchers often use to assess and improve the performance of learners is Contrastive Analysis (Lamidi, 2004). Contrastive Analysis is the study and comparison of two or more languages, for example, comparing English and Arabic, or Arabic, Yoruba and English, as would be demonstrated later in this study. This is done by examining the structural similarities and differences of the studied languages. There are two central aims of Contrastive Analysis; the first is to establish the inter-relationship of languages in order to create a linguistic family tree. The second aim is to aid the second language acquisition. The idea of Contrastive Analysis grew out of observing students learning a second language. Each student or groups of students tend to repeat the linguistic mistakes of the previous group. This leads to an assumption that mistakes are caused by students' first language interfering with the second. This interference happens because the students applied the first language rules to the second language much the same way children apply the rules of regular verbs to irregular ones.

Serious studies of Contrastive Analysis began with Robert Lado's 1957 book, Linguistics across Culture. Its central tenets and other observations on second language acquisition became increasingly influential in the 1960s and 1970s. It is built upon ideas set out in linguistic relativity, also known as the Sapir-Whorf Hypothesis which believes that language structures affect cognitive thinking. This invariably leads to the automatic transferring of one language rules to another. In this study, we shall bring out aspects of linguistic relations in each, as well as areas of differences between agreement features of Arabic and Yoruba languages. While the emphasis is on grammatical and phonological interference, we shall also discuss how knowledge of some linguistic rules in a language can affect the learning of some forms in the same language.

There have been very few contrastive studies on Arabic and some Nigerian languages. These include, among others, Yusuf (2005) which is a study of morphological and syntactic structures of Yoruba and Arabic, and Onibon (2011) which is a study that attempts to identify, describe, categorise, and diagnose some errors in Arabic essay writing of the non-Arabic speaking LASU students. However, its scope does not extend to the study of the phonological and agreement relations in Yoruba and Arabic. Therefore it becomes necessary to focus on the area in which learners often makes mistakes that are possibly due to their mother tongue interference.

In the following paragraphs, we shall delve on the contrastive analysis of illustrative samples of Arabic, English and Yoruba sentences at the grammatical level, 
focusing on Person Agreement, Gender Agreement, Number Agreement, SubjectVerb Agreement, Subject-Complement and Object-Complement Agreement respectively, with a view to highlighting the peculiarities and or differences between these languages at this level and possibly stimulate the awareness of the Yoruba learners of Arabic, who are learning Arabic as their second or third language to the distinctiveness of the grammar of their L1 which is Yoruba and their L2 and L3 which are English and Arabic as the case may be. In this connection, it is expected that, the incidence of linguistic interference of the $\mathrm{L} 1$ of the Yoruba learners of Arabicon their L2 or L3 would be minimised to the barest minimum.

\section{Grammatical Relations}

\section{Person Agreement}

Person Agreement refers to the syntactic features of a Noun Phrase, henceforth NP, with which verbs in the sentence must agree. Thus, a NP can be in the first, second or third person forms (Cowan, 1976, p. 11). The first person refers to the speaker; the second, the person being addressed; while the third, the person or thing being discussed. When NPs occur in any of these forms in Arabic, the verb whether auxiliary or main, agrees with it as in the following:

Arabic

1a. Ana: qawiyyun.

1b. Anta qawiyyun.

1c. Huwaqawiyyun.

2a. Ana:uhibbuar-ruza.

2b. Antatuhibbuar-ruza.

2c. Huwayuhibbuar-ruza.

2d. Antituhibbi:nar-ruza
English

"I am strong".

"You are strong".

"He is strong".

"I love rice".

"You love rice". (Second person singular masculine)

"He loves rice".

"You loves rice" (Second person singular feminine)

The verbs in (1) are linking verbs, which are implied, while "uhibbu" in (2) is a transitive verb. The pronoun in (1a) is in the first person singular and the verb agrees accordingly. In (1b) "anta" is second person masculine singular and therefore agrees with the singular verb as well, which is also implied. "Huwa" in (1c) is a third person masculine singular pronoun and takes the singular verb "is" which agrees with it. The situation is different in example (2), " $a n a^{\prime}$, viz the first person singular pronoun, has the form of verb "uhibbu" and "anta", the second person masculine singular pronoun, has the form of the verb "tuhibbu", clearly present different realisations of the verb with the introduction of " $u$ " and " $t u$ " prefixes respectively. In the case of the second person feminine singular, the simultaneous addition of the " $t u$ " prefix and an inflection viz: "bi: $n$ " marks a clear distinction of the verb thus, "tuhibbi: $n$ ", from the first and second person masculine singular classes. A quick look at some structures in Yoruba language may show the task ahead of a learner.

Yoruba English 


$\begin{array}{lll}\text { 3a. } & \text { Eminioluko re. } & \text { I am his teacher } \\ \text { 3b. } & \text { Iwo nioluko re. } & \text { You are his teacher } \\ \text { 3c. } & \text { Ounnioluko re. } & \text { S/he is his teacher. } \\ \text { 4a. } & \text { Mogbaowonaa. } & \text { I collected the money. } \\ \text { 4b. } & \text { Ogbaowonaa. } & \text { You collected the money. } \\ \text { 4c. } & \text { Ogbaowonaa. } & \text { S/he collected the money. }\end{array}$

Examples (3) and (4) show that Yoruba verbs are invariant whenever they occur with different NPs. It follows that the Yoruba learners of Arabic must learn each Arabic verb with its peculiarities and apply this knowledge to the rules of agreement as it concerns the pronouns.

\section{Gender Agreement}

Gender agreement on words is perceived as the concord relation holding between entities that share the same gender. In Arabic, gender is in two forms, namely, masculine and feminine (Cowan, 1976, p. 11), and both are morphologically realised on nouns and verbs in general. The feminine noun is formed from the masculine counterpart by suffixing with /----tun/ (otherwise known as ta:u al- marbu:tah). These distinctions are also reflected in personal, reflexive, possessive and demonstrative pronouns as reflected in the following examples:

$\begin{array}{ll}\quad \text { Arabic } & \text { English } \\ \text { Huwaka:tibun } & \text { He is a writer. } \\ \text { Hiyaka:tibatun } & \text { She is a writer. } \\ \text { Rau:fta:jirun } & \text { Rauf is a trader. } \\ \text { Fa:timahta:jiratun } & \text { Fatima is trader. }\end{array}$

These distinctions are also reflected in personal, reflexive, possessive and demonstrative pronouns as demonstrated in Examples (4) to (7):

Arabic

4a. Huwadarabanafsau

4b. Hiyadarabatnafsaha

5a. Qața?aFatta:hyadau

5b. Qața?atShukra: yadaha

6a. Ha: dha: walad

6b. Ha:dhihibint

7a. Dha:likkita:b

7b. Tilkamistarah
English

He beat himself

She hurt herself

Fatai cut his hand

Shukrat cut her hand

This is a boy

This is a girl

That is a book

That is a ruler

In the foregoing examples, the reflexives in (4) agree in gender with the subject of each sentence. In (5) to (7), the pronoun also agrees in number with the features of the NP subjects. In contrast to these Arabic structures, Yoruba has no gender specification of pronoun though the distinctions are inherent in such nouns (see examples (8) to (10)): 
Yoruba

8a. Otan ara re.

8b. O koara re niijanu.

9a. Ade ba ore re ja.

9b. Bimbobaegbon re ja.

10a. Omokurinkanniyi

10b. Omobirinkanniyi
English

$\mathrm{S} /$ he deceived himself/herself.

$\mathrm{S} /$ he cautioned himself/herself.

Ade fought his friend.

Bimbo fought her brother.

This is a boy

This is a girl

In these examples, there is no gender distinction in the personal (8), reflexive (9) and possessive (10) pronouns. This explains why learners of Arabic make mistakes on gender distinctions saying huwa (he) when they mean hiya (she). We may argue that the personal pronoun " $O$ " and the possessive " $r e$ " interfere in learners' performance. The same applies to others.

\section{Number Agreement}

Number refers to the quantity of an NP in an expression. Words can be singular, dual and plural. In colloquial Arabic the dual is almost confined to periods of time and the dual parts of the body. In Arabic dual refers to two things of a kind. The nominative dual ending is iان.e.a:n and the accusative and genitive ending i.e.ayn added to the singular of the word after removal of the case ending as shown in Example (11):
Arabic
English
11a.كتابانkita:ba:ni
"Two books" (nominative case)
11b.كتابينkita:bayni
"Two books" (accusative and genitive cases)

The dual feminine forms in Arabic also attract the suffix (a:n) or (ayn) as the case may be after the feminine suffix(t) as shown in Example (12):

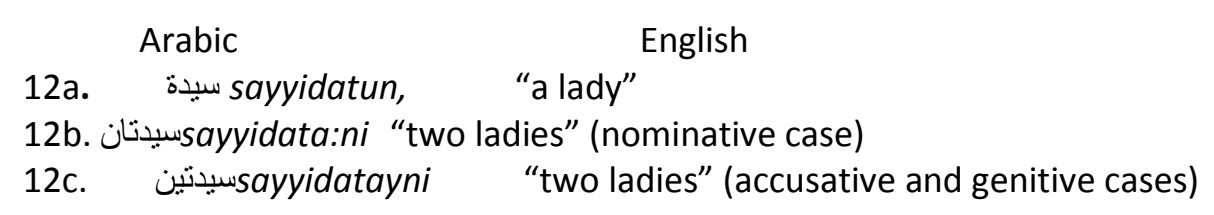

There are two basic types of plural in Arabic, namely, the sound plural, which is practically confined to participles and nouns indicating professions or habitual actions, and secondly the broken plural, which is prone to many patterns, by altering of vowels within or outside the framework of the radical consonants. The masculine endings of the sound plural are realised byن (nominative)and ين (accusative and genitive). In Arabic the verb of a sentence usually comes first and such a sentence is regarded as a verbal sentence. In the feminine sound plural, the ending/closed ta:u ( $)$ becomes "a:tun" (ات) in the nominative and "a:tin" (ات) in the accusative and the genitive cases. Other feminine endings are $\checkmark(a)$ and a,'i u (when singular) suffixed to last radical of the word. Both of these are without "nunation" e.gكرى.وصحراءa desert. In Yoruba language there are no affixes 
marker indicating singular, dual or plural, although there are word numbers indicating the quantity as exemplified below:

\section{Yoruba}

Fun mi niiwe yen

Fun mi niawoniwe yen

Fun mi niiwemeji yen
English

Give me that book

Give me those books

Give me those two books

Therefore, there is tendency for Yoruba students to encounter problems in understanding the grammar of quantity in Arabic.

\section{Subject-Verb Agreement}

The most approved word order in grammatical Arabic is verb-subject-object, (VSO) as shown in Examples (14) to (17):

Arabic

14. Katabaal-mu?allimad-darsaala:as-sabbu:rati, The teacher wrote the lesson on the blackboard

But often the subject occurs in the initial position of a sentence, e.g.

15. Al-khabba:zukhabazafi'lfurni.

The baker baked the bread in the oven.

If the verb comes first in the sentence it must always be in the singular even though the subject may be plural or dual, and it must agree with the subject gender. See Examples (16) to (19):

\section{Arabic}

English

16a. Saraqaal-lusu:sma:laat-ta:jiri. The robbers stole the merchants' property.

16b. Dhahaba:ar-rajula:niila:as-su:qi. The two men went to the market.

16c. Ghasalnaat-talabatuthiya:bahunna. The students washed their clothes.

But if the subject precedes the verb then the verb must agree with it in number as well as in gender, e.g.

17a. Al- lusu:ssaraqu: ma:laat-ta:jir.

The robbers stole the merchants' property

17b. Ar-rajula:nDhahaba:ila:as-su:q. The two men went to the market 17c. At-talabatughasalnathiya:bahunna. The students washed their clothes.

In (17), the number or gender marking on verbs should be emphasised for subjectverb concord in Arabic. This is because the verb forms in Yoruba do not display such distinctions as shown in Examples (18) and (19): 
Yoruba

18a. Kasali $n$ jo.

18b. KasaliatiAdio $n$ jo.

19a. Mon $n$ ko.

19b. O nko.

19c. $A \cap$ ko.

19d. Won $n$ ko.
English

"Kasali dances/is dancing"

"Kasali and Adio dance/are dancing".

"I write/am writing".

"You write/are writing".

"We write/are writing".

"They write/are writing".

In essence, whether the NP is singular or plural as in (18), the verb and its auxiliary remain uninflected. The same is also true of pronouns irrespective of whether they are singular $(19 a \& b)$ or plural $(19 c \& d)$. It follows that the errors of subject-verb concord committed by the Yoruba learners of Arabic especially in the area of third person singular emanate from the Yoruba Mother Tongue (MT) interference.

\section{Subject-Complement and Object-Complement Agreements.}

In Arabic, number agreement is also required between the subject and its complement in some structures. Consider for instance (20):

Arabic

20a. Innarajulata:jirun

20b.Innarija:Iata:jiru:na
English

"the man is a trader". "the men are traders".
Yoruba

Okunrinnaa je onisowo.

Awonokunrinnaa je onisowo

This rule does not apply in the Yoruba version (translation of 20a and b). Although the NP subjects in (20a \&b) are singular and plural respectively, the complement onisowo "trader" remains the same. Only the contexts show that one is singular and the other is plural. This same phenomenon occurs in agreement relations between an object and its complement.

Arabic

21a. Samaytual-waladaat-tayyib.

21b. Wasafaal-mu'alimuat-tula:bashu'ara:a. "The teacher called the students poets."

Yoruba

22a. Mo so omonaaniToyyibu.

22b. Olukonaapeawonakekonaaniakorin.

As shown in (22), awonakeko "the students" is pluralised by introducing another word "awon" but akorin "poets" which is contextually plural is not marked morphologically. It follows that the number agreement in Yoruba is less recognised in surface form unlike in Arabic where singular, dual and plural are represented both in oral and writing forms. 


\section{Phonetic and phonological relation}

The absence of original equivalents of some Arabic sounds/phonemes in the sound system of several languages such as the Yoruba, Hausa and English to mention a few, basically, account not insignificantly for the various linguistic fallacies prevalent among non-native users of Arabic in Nigeria in general and south western Nigeria in particular (Mogaji, 2009b). While teaching the Arabic sounds to foreign learners, it is of primary importance to teach the contrastive phonological elements in the language. As it has been indicated earlier in this paper, the traditional approach of following the alphabetical sequence (which does not take into consideration the grouping of the sounds according to their basic relations) in teaching the Arabic phonemes is no longer viable. Teaching the Arabic sounds according to their manner of production would be in line with the essential principles of language teaching. Since this kind of approach takes into account the basic relations between members of each pair of sounds, it will help the foreign learners, like the Yoruba speakers, to distinguish between them. In this way better results may be achieved in the teaching of oral-communication in Arabic as a foreign language.

Consequent upon the above, misrepresentation of Arabic sounds/phonemes is prevalent in the south western part of Nigeria. This is due to the poor background of most non-native users in Arabic phonetics and phonology. The reason for this may be traced to the incompetence of the teachers and learners of Arabic in accounting for the sounds and phonemes of a nascent discipline yet in its inchoate state in a foreign environment (Mogaji, 2009a). In the following section, a brief contrastive phonological analysis of Arabic and Yoruba consonants is presented to aid identification of areas of difficulty confronting the Yoruba students in learning Oral Arabic communication.

\section{Sample of phonetic differences}

Mogaji (2009a) had extensively evaluated some phonetic peculiarities subsisting between the Arabic and Yoruba languages and which inadvertently account for aspects of linguistic solecism prevalent amongst the Yoruba speakers of Arabic.

(a) The /dhal/ (ذ), /th/ (ث), /tz/ (ظ), /ts/ (ص) and /z/ (j) sounds/phonemes: Several Yoruba users of Arabic articulate these sounds as /s/ or (w). Thus, the /dh/ sound in words such as al-ladhi:,al-ladhi:na,dha:lik,dhikr,e.t.c is erroneously articulated as /s/ or (w). The /th/ sound in words such as thawba:n, tha:ni:, tha:lithetc is erroneously articulated as $/ \mathrm{s} /$. The $/ \mathrm{tz} /$ sound in words such as tzila:I,tza:limu: $n$, tza:lim is wrongly articulated as $/ \mathrm{s} /$. The /ts/ sound in words such as haftsah, tsala:h, tsawm is wrongly articulated as /s/. The /z/ sound in rizq, fawz,zakariya: is erroneously articulated as /s/.

(b) The /q/ (ق) sound/phoneme: Several Yoruba users of Arabic articulate this sound as /k/. Hence the /q/ sounds in words such as qamar,qudrahetc is incorrectly articulated as $/ \mathrm{k} /$ or (ك)).

(c) The $/ \mathrm{h} /(\tau), / \mathrm{kh} /(\dot{\zeta}), />/$ (દ) sound/phonemes: Many Yoruba users of Arabic articulate these sounds as $/ a /$, hence the /h/ sound in words such as hali:mah, hamdalah, ha:midetc is erroneously articulated as /a/. The / kh/ sound in words 
such as al-khami:s,khadi:jah, kha:lide.t.c is erroneously articulated as /a/.The />/ sound in words such as shu'aib, 'abd, 'a:limetc is erroneously articulated as/a/ or ( $s)$.

(d) Shortening of long vowels:

There are three long vowels in Arabic language meaning, alif( $(1), w a: u(g)$ and ya:u(ى). Shortening of these otherwise long vowels is another area where Yoruba users of Arabic commit phonological errors. Examples of this phenomenon include:

\begin{tabular}{llc} 
Arabic & \multicolumn{2}{c}{ Yoruba } \\
Ha:mid & pronounced as Amidu \\
Jali:l & " & Jalili \\
'Azi:z & " & Lasisi/Laisi \\
Fa:timah & " & Fatimo \\
Hawa:u & " & Awau \\
Thauba:n & " & Saobana \\
Kari:m & " & Karimu \\
Wa:hid & " & Waidi \\
Sala:m & " & Salami \\
Sira:j & " & Suraju
\end{tabular}

From the foregoing analysis, we would see that most of the examples listed above have undergone phonological or structural changes. By and large, these changes are due to the interference of Yoruba language. On the phonological level, what motivates the phonological changes is the non-existence of some consonants in Yoruba but found in Arabic. These can be found among plosive and fricative sounds. The pharyngalised dental-alveolar plosives/t $/(b)$ and $/ d /$ (ض) as well as the uvular plosive/q/(ق) are not found in Yoruba. Thus, the Yoruba speakers of Arabic often substitute these sounds with /t/, /d/ or /I/ and / $\mathrm{k} /$ respectively as shown below:

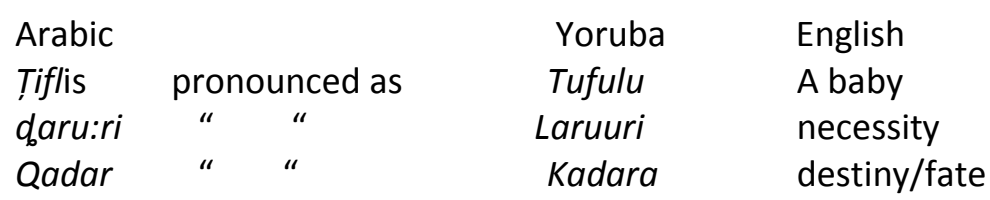

The glottal stop /?/ is not available in Yoruba, it is therefore dropped in the Arabic word as shown below:

Arabic

Ad-du?a: is pronounced as

Sama: is pronounced as

\begin{tabular}{ll}
\multicolumn{1}{c}{ Yoruba } & English \\
Adua/Adura & "prayer" \\
Sanma & "sky" by Yoruba learners
\end{tabular}

The dental fricative /th/ $(\dot{H}$ ) and pharyngealised dental fricatives $/ / /(j)$, and (tz)(ظ) do not exist in Yoruba. Hence, the phonemes /t/ and /s/ usually replace these sounds respectively as reflected in the following examples: 


$\begin{array}{lll}\text { Arabic } & \text { Yoruba } & \text { English } \\ \text { Ath-thulatha: } \text { pronounced as } & \text { atala:ta } & \text { "Tuesday" } \\ \text { Wa?z pronounced as } & \text { wa:si } & \text { "sermon/preaching" }\end{array}$

Due to the predominant CV syllable structure of Yoruba language, the syllable consonant cluster, whether initial, medial or final, are not present in Yoruba. Structural changes in Arabic words are motivated by a tendency either to drop one of the consonants or to insert vowel sounds between the Arabic clusters to make it conform to the Yoruba syllable patterns. Thus, the following examples:

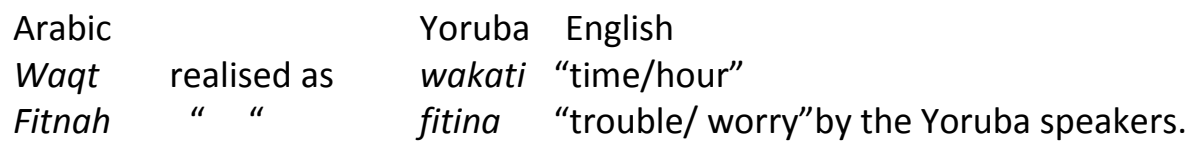

From the above analysis, it is clear that for a more effective teaching of oral communication in Arabic as a foreign language, the linguistic features of both Arabic and the Yoruba language of the learner must be analysed, compared and considered by the Arabic language instructors/teachers. The analysis and comparison could serve two major purposes:

1. They could serve as a guide to the Arabic teacher, and

2. They could serve as a basis for preparing text book materials that is suitable for teaching Oral-Arabic as a foreign language.

The instructor should focus more on the areas of differences identified above whereas the students should be allowed to have more hours of practice on those areas identified as difficult areas or areas of differences.

\section{Conclusion}

Having compared Arabic and Yoruba agreement features, we observed that Yoruba agreement system is not as elaborate as that of Arabic. Arabic combines both structural and semantic features in its agreement feature. The onus, however, lies on the teacher to emphasise the teaching aspect of grammar and phonology as the incidence of misuse is one of the most obvious violations of the rules of grammar. It should be noted that the errors committed by the learners, generally, are not limited to the realm of phonology alone but also extends to the orthographical aspects as shown by the transliterations above. As Mogaji (2009a) observes, application of relevant educational technology resources in the teaching and learning of Arabic phonetics/phonology would have made the whole exercise more productive and beneficial to all the parties concerned.

The recurrent linguistic difficulties of any individual student reflect the similarities and differences between his or her mother tongue and the foreign language $s /$ he is learning. Therefore, it seems that the most appropriate materials for teaching a foreign language to non-native speakers are those which embody a 
bilingual comparison of their mother tongue and the target language. Hence, comparisons between Yoruba and Arabic, for the purpose of demonstrating their similarities and differences in the use of linguistic features, may be helpful to the teaching and learning of oral-communication in Arabic. One fact that should not be ignored is that every native speakers of any language has acquired a set of linguistic habits in learning it. Therefore, in the course of learning a foreign language, such old habits not only remain with him or her, but, also, colour the features of the new language. It is for this reason that a Yoruba person, a Hausa person and an English person speak Arabic with their respective accent and so on. A native speaker of Yoruba has formed habits in the phonological, lexical, and grammatical features of the language and in attempting to learn Arabic; therefore, s/he may make mistakes in all the three areas.

\section{References}

Abubakre, R. D. (1983). Aspects of the diffusion of Arabic to Yoruba. Journal of the Nigerian Association of Teachers of Arabic and Islamic Studies NATAIS, 11(1), 13-14.

Cowan. D. (1976). Modern literary Arabic. Beirut, Lebanon: Islamic Publication Press.

Fafunwa, A. B. (2008). History of education in an open economy: Nigeria, 1945-1966. Cambridge: Cambridge University Press.

Gbadamosi, T.G.O. (1978). The growth of Islam among the Yoruba 1841-1908 $\left(1^{\text {st }}\right.$ ed.). London: Longman.

Hymes, D. (1974). Studies in the history of linguistics, tradition and paradigm. Bloomington: Indiana University Press.

Lamidi, T. (2004). Agreement relations in English and Yoruba. In R. O. Oriaku (Ed.), Ibadan Journal of English Studies, 1 (35-53). Nigeria: University of Ibadan.

Malik, S. H. A. (1980). Towards the improvement of the teaching of Arabic as a foreign language. Al-fikri, Journal of the Department of Arabic and Islamic Studies, University of Ibadan, 1(1), 21-27.

Malik, S. H. A. (1990). Arabic in Nigeria: A veritable heritage. In E. Agwonorobo \& E. Eruvbetine (Eds), Aesthetics and Utilitarianism in Language and Literature (pp. 27-37). Ojo-Lagos: Lagos State University.

Malik, S. H. A. (1999). Arabic, the Muslim prayers and beyond. An inaugural lecture (pp. 15-17). Ibadan: University of Ibadan.

Mogaji, T. A. (2009a). Educational technology and Arabic studies: A review. Journal of Oriental and African Studies 18, 277-288.

Mogaji, T. A. (2009b). Arabic and the socio-cultural development of Nigeria: An assessment. LASU Journal of Humanities, 6, 160-176.

Onibon N. O. (2011). Error analysis as a method of teaching writing skill in Arabic class in a non-Arabic setting. Al-ishra:q, Journal of Arabic and Islamic Studies, 4, 20-36.

Yusuf, O. (2005). Fundamentals of syntax and the study of Nigerian languages (pp. 8-10). Nigeria: Ijebu-Ode Shebiotimo Poblication. 